\title{
Evaluation of Atmospheric Pollutant Emission Efficiency Based on SBM-Undesirable Model — Taking PM2.5 as an Example
}

\author{
She xiaohe ${ }^{1}$, Wang Yingying ${ }^{2}$, Cao Haimin ${ }^{1}$, Yuan Fangying ${ }^{1,}{ }^{*}$, Ai Wei ${ }^{1}, H_{e}$ Qi $^{1}$, Yang Xiaoyan ${ }^{1}$ and Sun Juan ${ }^{1}$ \\ ${ }^{1}$ School of Management Studies, Shanghai University of Engineering Science, Shanghai, China \\ ${ }^{2}$ Department of philosophy, Nanjing University, Nanjing, China
}

\begin{abstract}
At present, China's haze is becoming more and more serious. How to reduce haze emission is an urgent problem in China's environmental governance. This paper uses the SBM-Undesirable model, adopting 5 inputs indexes(coal, oil, gas, labor and capital), and 2 outputs indexes (GDP and PM2.5 emissions) as expected output and unexpected output respectively, to calculate the emission efficiency of PM2.5 in China's 29 provinces. Based on the efficiency evaluation results of SBM-Undesirable model, the reasons for the inefficiency of PM2.5 emission are analyzed. The redundancy rate of investment, the insufficient rate of expected output and the redundancy rate of undesirable outputs are calculated. Results showed that: (1) Most provinces with high PM2.5 emission efficiency are concentrated in the eastern region, while the PM2.5 emission efficiency in the central and western regions is relatively low. (2) The redundancy rate of input variables and undesirable output of the eastern region is lower than that of the western and based on SBM-Undesirable model central regions. This is likely to have a great relationship with the economic development and the high level of technology in the eastern region. This study provides a reference for reducing the haze theory and providing empirical support for the government's haze reduction.
\end{abstract}

\section{Introduction}

In recent years, large-scale haze weather in China has increasingly aroused the high attention of the society at home and abroad to the air pollution problem. In such a context, how to take effective measures to meet the challenges brought by atmospheric pollution such as haze has become an important issue of common concern for government departments and academia ${ }^{[1]}$.

A large number of scholars try to control the emission of haze pollutants from the source by understanding the causes of haze, but the source system and formation process of haze are extremely complicated (Cui et al., 2016; Wang Zhijuan et al., 2012; Zhang Chan et al., 2014), the inability to effectively respond to the disease makes the prevention and control of air pollution more difficult. If we can use quantitative analysis tools to study the emission reduction indicators of air pollutants from the perspective of management, on the one hand, we do not need to clarify the source of air pollution in the short term and its forming process, on the other hand, we can provide empirical support for the emission reduction indicators and their ranges regulated by the government, which undoubtedly has a good reference value and practical significance ${ }^{[2}$.

This paper aims to treat the undesired output PM2.5 as the input index, took China's provinces (autonomous regions, municipalities directly under the central government) as the decision-making unit, took PM2.5 as the representative index of haze, used the data envelopment model (DEA) evaluation method to evaluate the PM2.5 emission efficiency of each province, measured the input redundancy rate and the undesired output redundancy rate of each province, so as to provide new ideas for energy conservation and emission reduction work concerning China's air pollution.

\section{SBM-Undesirable Model}

There is a big drawback in traditional DEA model, which belongs to the radial direction and angle DEA measurement method, and this method will lead to the 'Relaxation' problem of input factors. When there is non-zero relaxation of input or output, the radial DEA model will cause high productivity, while the angle DEA model only focuses on the input angle or output angle; thus, the calculated efficiency results are not accurate enough ${ }^{[3]}$.

In order to overcome the shortcomings of the radial and angular DEA models, Tone (2004) built the SBMUndesirable model by introducing undesired outputs into the objective function based on the SBM-DEA model. The SBM-Undesirable model could not only evaluate the environmental efficiency value of each decision unit considering undesired output, but also could calculate the input redundancy ratio and expected output of a

\footnotetext{
* Corresponding author: 23128757@qq.com
} 
decision unit with an efficiency of 1 , and a decision unit with an efficiency other than 1. Insufficient rate and excess rate of undesired output, so as to obtain the corresponding efficiency improvement space of each decision-making unit. When the efficiency of the decision unit is not 1 (ie. $\mathrm{p}^{*}<1$ ), referring to the research by Cooper et al., based on the relaxation variables, the source of the inefficient loss considering the undesired output can be decomposed into:

\subsection{Radial movement}

$I E_{x}=\frac{1}{M} \sum_{m=1}^{M} s_{m}^{x} / x_{m 0}$

which indicates the shrinkable proportion of input elements;

\subsection{Insufficient expected output}

$I E_{g}=\frac{1}{O+R} \sum_{o=1}^{O} s_{o}^{g} / y_{n o}^{g}$

which indicates a reduction ratio in the expected output;

\section{3 undesired output redundancies}

$I E_{b}=\frac{1}{O+R} \sum_{r=1}^{R} s_{r}^{b} / y_{r o}^{b}$

which represents the expandable proportion of expected output $^{[4-6]}$..

\section{Data description}

\subsection{Index description}

\subsubsection{Input indicators}

(1) Production function

This paper draws on the production function proposed by Cobb-Douglas. And PM2.5 index is added to the output side of the production function, and environmental and energy indexes related to PM2.5 output are added to the input side. The expression of the production function is expanded as follows:

$Y_{j}=A_{j} K_{j}^{\alpha} L_{j}^{\beta} C_{j}^{\chi}$

indicates the output of $\mathrm{j}$ region, indicates the broad technology of $\mathrm{j}$ region, indicates the capital input of $\mathrm{j}$ region, indicates the labor input of $\mathrm{j}$ region, and indicates the environmental and energy input related to PM2.5 output in $\mathrm{j}$ region, and and indicate the output elasticity of environmental and energy input indicators related to capital, labor, and PM2.5 output, respectively.

(2) Energy input indicators

How to choose appropriate environmental and energy indicators is the key issue of this study. This paper draws on previous studies and combines the availability of data to select three energy indicators: coal, oil and gas, as input indicators. Among them, coal indicators mainly include the consumption of coal and coke, oils include the consumption of raw oil, gasoline, kerosene, diesel, and fuel oil, and gas indicators are the consumption of natural gas.

\subsubsection{Output indicators}

This paper sets up two output indicators, one is the expected output indicator GDP, and the other is the undesired output indicator ('Provincial Population Weighted PM2.5 Concentration'* 'Provincial Land Area' / 'The atmospheric capacity of PM2.5 in each province under national PM2.5 standard constraint')

\subsubsection{Evaluation indicators of smog}

PM2.5 is one of the main components of haze. China did not formally count PM2.5 data until 2012, so it is difficult to obtain the data before 2012. In this paper, the population weighted PM2.5 concentration value of each province in China in 2010 is used under the condition of $35 \%$ humidity ${ }^{[7]}$.

\subsection{Data source}

The energy consumption data is taken from the China Energy Statistical Yearbook (2010). The fossil energy consumption is taken from the coal, oil and natural gas consumption of the energy balance tables of the provinces (2010). The compensation of laborers is expressed by the average salary of employees, while the capital investment is replaced by fixed asset investment, the average salary of employees, fixed asset investment, and provincial GDP data are taken from China Statistical Yearbook (2010).

\section{Empirical analysis}

In this chapter, two empirical results are analyzed: (1) Based on SBM-Undesirable model, the environmental efficiency of 29 provinces and cities in China is calculated. (2) Based on the SBM-Undesirable model, the environmental efficiency assessment results also calculate the input redundancy rate and the undesired output excess rate.

\subsection{Efficiency evaluation based on SBM- Undesirable model}

MaxDEA software was used and the SBM-Undesirable model was involved to measure efficiency, we could know that:

(1) PM2.5 emission efficiency measured in 29 provinces and cities based on the SBM-Undesirable model. The cities of the 17 provinces (Beijing, Tianjin, Liaoning, Shanghai, Jiangsu, Zhejiang, Anhui, Jiangxi, Shandong, Henan, Hubei, Hunan, Guangdong, Guangxi, Hainan, Guizhou, and Yunnan) have a production efficiency considering undesired output of 1 . This shows that compared to other cities, these cities with an efficiency of 1 have reached the efficiency frontier of their own model construction. The allocation of factors has reached the optimal level, and the protection of resources and the environment has been well taken into account along with economic development. The remaining provinces and 
cities with efficiency other than 1 have low PM2.5 emission efficiency and are at inefficient levels. The number of input and output factors needs to be adjusted to improve efficiency to reach their respective effective states.

(2) Including the above-mentioned cities in 17 provinces with the emission efficiency of 1 , Hebei province and Fujian province also consider the efficiency value of undesired output above the national average efficiency level, while the efficiency value of Shanxi, Inner Mongolia, Jilin, Heilongjiang, Sichuan, Shaanxi, Gansu, Qinghai, Ningxia and Xinjiang provinces considering undesired output is below the national average efficiency level. It can be seen that most provinces with high efficiency are concentrated in the eastern region, and the PM2.5 emission efficiency in the central and western regions is relatively low.

\subsection{Potential improvement of PM2.5 emission efficiency considering undesired output}

According to formula (1), we could know the PM2.5 emission efficiency calculated by the SBM-Undesirable model. When the PM2.5 emission efficiency value $\rho^{*}<1$, the magnitude of the slack $S^{x}, S^{b}, S^{g}$ can reflect the cause of the inefficient loss. This paper divides the slack of each input variable of each province and city' $S^{x}$ in China by the corresponding input index value of each province and city in 2010 to obtain the input redundancy ratio. The PM2.5 pollution emission redundancy rate is obtained by dividing the slack in the GDP output value of each province and city by the corresponding GDP output value of each province and city to obtain the GDP output deficiency rate. The calculation results are shown in Table 1. It could be known from the table:

(1) From the perspective of the production process, the output inadequacy rate of GDP output value of each province and city is zero, and there is a certain degree of redundancy in each input factor and PM2.5 emissions. Hence, the insufficient of available GDP output is not the reason for the ineffective production efficiency of some provinces and cities considering undesired output. The two aspects of input and undesired output caused by PM2.5 emissions indicate that the current low environmental efficiency in China is mainly caused by excessive resource consumption and excessive environmental pollutant emissions.

(2) From a nationwide perspective, the main influencing factors of efficiency loss are the input of 'average wages of employees', 'natural gas', 'coal', and 'oil'. Due to the current phenomenon of a large surplus of rural labor in China, labor input is an important cause of inefficient losses, and 'coal', 'oil' and 'natural gas' are overinvested. We must realize the further transformation of the economic growth mode, from extensive growth mode to intensive growth mode, improve energy efficiency, and vigorously advocate the construction of 'resourcesaving society' and 'environment-friendly society'.

(3) From the perspective of different regions, the reasons for the loss of undesired output inefficiency rate are different. The main influencing factors of the loss of inefficiency rate in the eastern region are 'average wage of employees' and 'coal' input. The main influencing factors of the loss of inefficiency rate in the central region are 'coal', 'oil', 'average wage of employees' and 'natural gas' input. The main influencing factors of the inefficiency loss in the western region are 'average wage of employees', 'natural gas', 'coal', 'oil'. The results show that the eastern region has the lowest input redundancy and undesired output redundancy, the central region has the middle input redundancy and undesired output redundancy, and the western region has the highest input redundancy and undesired output redundancy. This may be related to the higher level of economic development and advanced production technology in the eastern region compared with other regions. By analyzing the causes of efficiency loss of undesired output, we can clearly understand the main factors that cause the inefficiency loss of provinces, cities and regions, and further formulate corresponding targeted policies for improving efficiency.

\section{Conclusions and suggestions}

In this study, SBM-Undesirable model is used to evaluate the emission efficiency of PM2.5 in 29 provinces of China, and the causes of PM2.5 emission inefficiency are also further analyzed, and the input redundancy rate and undesired output redundancy rate of each province are calculated. According to the results of this study, the following conclusions and suggestions are drawn.

From the perspective of local governments, local governments at all levels need to abandon the old concept of GDP supremacy, develop new concept of green GDP, and further strengthen their respective emission reduction obligations and requirements.

Some provinces with low PM2.5 emission efficiency, such as Shaanxi, Gansu, Xinjiang, Inner Mongolia, Heilongjiang and other provinces should proactively formulate industrial policies that are in line with the actual development of the region, and reduce the development approval of high-polluting, high-energyconsuming and high-emissions enterprises volume, to complete the bottom line goal of 'haze reduction' work. For some provinces with high emission concentration, such as Shandong, Henan, Hebei, etc., they could try to designate a paid pollutant discharge mechanism, gradually reduce or even eliminate heavy polluting enterprises, accelerate the transformation and upgrading of production capacity of enterprises, and promote the traditional heavy polluting enterprises to low pollution and green, environmentally friendly enterprises. Fundamentally speaking, it is necessary to optimize the performance evaluation mechanism for local governments, change the development concept of officials, and overcome obstacles from interest groups. Meanwhile, it is necessary to give environmental protection departments and other non-governmental organizations more supervision power and expand supervision channels and methods, as well as coordinate various social forces to jointly manage the smog. 
From the perspective of economic development mode, the mode of economic development needs to be further changed to promote substantial and sustained reduction of PM2.5 emissions.

The improvement of regional air quality is realized along with the change of economic development mode. While maintaining steady economic

growth, and significantly reducing smog pollution, we must actively carry out the transformation of social and economic development. At the macroeconomic structural level, China needs to construct an economic structural system including sustainable development investment and consumption urgently, gradually reduce its dependence on heavy pollution and high consumption industries, and improve the efficiency of PM2.5 and other local emissions. For the development of pollution industry itself, improve the technical level and the industrial output value while reducing the overall energy consumption and PM2.5 emissions. At the industrial layout level, it is necessary to gradually evacuate the capacity of heavy chemical industries in areas such as Beijing-Tianjin-Hebei, the Yangtze River Delta, and the Pearl River Delta.

\section{Acknowledgment}

Supported by Youth Program of National Natural Science Foundation of China (Project No. 71704102)

Supported by MOE (Ministry of Education in China) Youth Foundation Project of Humanities and Social Sciences (Project No. 15YJCZH060)

\section{References}

1. Charnes, A., Cooper, W. W., Rhodes, E. Measuring the Eciency of Decision Making Units[J].European Journal of Operational Research, 1978, 2(6):429444.

2. Feng S, Gao D, Liao F, et al. The health effects of ambient PM2.5 and potential mechanisms[J]. Ecotoxicology \& Environmental Safety, 2016, 128:67-74.

3. Cui M, Chen Y, Tian C, et al. Chemical composition of PM2.5 from two tunnels with different vehicular fleet characteristics[J]. Science of the Total Environment, 2016, 550(7):123-132.

4. Wu X, Chen Y, Guo J, et al. Inputs optimization to reduce the undesirable outputs by environmental hazards: a DEA model with data of PM2.5, in China[J]. Natural Hazards, 2018, 90(1):1-25.

5. Zhang Y, Schauer J J, Zhang Y, et al. Correction to Characteristics of Particulate Carbon Emissions from Real-World Chinese Coal Combustion. [J]. Environmental Science \& Technology, 2017, 42(14):5068-5073.

6. Pei B, Wang $\mathrm{X}$, Zhang $\mathrm{Y}$, et al. Emissions and source profiles of PM2.5, for coal-fired boilers in the Shanghai megacity, China[J]. Atmospheric Pollution Research, 2016, 7(4):577-584.

7. Pei B, Wang $\mathrm{X}$, Zhang $\mathrm{Y}$, et al. Emissions and source profiles of PM2.5, for coal-fired boilers in the Shanghai megacity, China[J]. Atmospheric Pollution Research, 2016, 7(4):577-584.

Table 1. Inefficiency of PM2.5 Emission in China (2010)

\begin{tabular}{|c|c|c|c|c|c|c|c|}
\hline \multirow{2}{*}{ Province } & \multicolumn{5}{|c|}{ Input Redundancy Rate } & \multirow{2}{*}{$\begin{array}{c}\begin{array}{c}\text { Output } \\
\text { redundancy rate }\end{array} \\
\text { GDP }\end{array}$} & \multirow{2}{*}{$\begin{array}{c}\begin{array}{c}\text { Unexpected } \\
\text { output } \\
\text { redundancy rate }\end{array} \\
\text { PM2.5 emission }\end{array}$} \\
\hline & $\begin{array}{c}\text { Fixed } \\
\text { Capital } \\
\text { Investment } \\
\end{array}$ & $\begin{array}{c}\text { Average } \\
\text { wage of } \\
\text { employees }\end{array}$ & $\begin{array}{l}\text { Natural } \\
\text { gas }\end{array}$ & Coal & oils & & \\
\hline Tianjin & $61.25 \%$ & $80.86 \%$ & $38.71 \%$ & $54.43 \%$ & $46.42 \%$ & $0.00 \%$ & $81.16 \%$ \\
\hline Hebei & $0.00 \%$ & $12.60 \%$ & $0.00 \%$ & $39.08 \%$ & $16.98 \%$ & $0.00 \%$ & $0.00 \%$ \\
\hline Nei Monggol & $43.00 \%$ & $96.64 \%$ & $70.76 \%$ & $72.61 \%$ & $62.18 \%$ & $0.00 \%$ & $70.76 \%$ \\
\hline Jilin & $45.44 \%$ & $38.71 \%$ & $33.97 \%$ & $50.27 \%$ & $33.77 \%$ & $0.00 \%$ & $70.50 \%$ \\
\hline Heilongjiang & $0.00 \%$ & $0.00 \%$ & $24.84 \%$ & $20.55 \%$ & $63.22 \%$ & $0.00 \%$ & $32.72 \%$ \\
\hline Fujian & $22.10 \%$ & $48.90 \%$ & $0.00 \%$ & $0.00 \%$ & $0.00 \%$ & $0.00 \%$ & $5.31 \%$ \\
\hline Sichuan & $26.16 \%$ & $19.89 \%$ & $93.94 \%$ & $0.00 \%$ & $10.39 \%$ & $0.00 \%$ & $47.55 \%$ \\
\hline Shaanxi & $12.07 \%$ & $99.41 \%$ & $70.73 \%$ & $14.32 \%$ & $79.13 \%$ & $0.00 \%$ & $51.03 \%$ \\
\hline Gansu & $17.47 \%$ & $85.35 \%$ & $82.56 \%$ & $51.36 \%$ & $81.62 \%$ & $0.00 \%$ & $80.83 \%$ \\
\hline Qinghai & $30.00 \%$ & $99.90 \%$ & $99.90 \%$ & $99.91 \%$ & $32.00 \%$ & $0.00 \%$ & $100.00 \%$ \\
\hline Ningxia & $50.74 \%$ & $98.13 \%$ & $97.96 \%$ & $93.92 \%$ & $68.00 \%$ & $0.00 \%$ & $91.05 \%$ \\
\hline Xinjiang & $16.12 \%$ & $83.92 \%$ & $85.50 \%$ & $76.40 \%$ & $63.75 \%$ & $0.00 \%$ & $99.31 \%$ \\
\hline China & $27.03 \%$ & $63.69 \%$ & $58.24 \%$ & $47.74 \%$ & $46.45 \%$ & $0.00 \%$ & $60.85 \%$ \\
\hline Eastern China & $27.78 \%$ & $47.45 \%$ & $12.90 \%$ & $31.17 \%$ & $21.13 \%$ & $0.00 \%$ & $28.82 \%$ \\
\hline Central China & $29.48 \%$ & $45.12 \%$ & $43.19 \%$ & $47.81 \%$ & $53.05 \%$ & $0.00 \%$ & $57.99 \%$ \\
\hline Western China & $25.42 \%$ & $81.10 \%$ & $88.43 \%$ & $55.98 \%$ & $55.81 \%$ & $0.00 \%$ & $78.29 \%$ \\
\hline
\end{tabular}

Note : (1) Considering the production efficiency of undesired output of 17 provinces and cities(including Beijing, Shanghai, Jiangsu, Shanxi, Liaoning, Zhejiang, Anhui, Jiangxi, Shandong, Hubei, Hunan, Guangdong, Guangxi, Hainan, Henan, Guizhou and Yunnan) is 1, this table does not include these 17 regions; (2) Eastern China includes Hebei, Tianjin and Fujian; (3) Central China includes Heilongjiang, Jilin and Nei Monggol; (4) Western China includes Sichuan, Gansu, Shaanxi, Qinghai, Ningxia and Xinjiang. 